\title{
Abortion access grim in English Canada
}

$\mathrm{C}$ anadian women seeking to end unwanted pregnancies face wide gaps in access to abortion and have little choice in the technique used, a landmark study reveals.

Access to abortion depends largely on where you live, with wide disparities among provinces and between rural and urban locations, according to a new survey of abortion services in Canada. And with few options for drug-induced abortion - the preferred method for ending a pregnancy during the first trimester in the United States and many European peer nations - 96\% of abortions in Canada are done surgically.

Researchers presented initial results of the 2012 survey, which was funded by the Society of Family Planning, at the recent Family Medicine Forum in Québec City. The venue was germane; the study shows that 46 of Canada's 94 abortion facilities are located in Quebec. The province is also a leader in equitable access; half of its abortion facilities are in rural areas, and there's at least one facility in every health region.

No other province comes close to providing the same level of access. British Columbia has 16 facilities located in hospitals, community health centres and doctors' offices; half of these are in rural areas. There are 16 facilities in Ontario, 8 among Alberta, Saskatchewan and Manitoba, 4 in Atlantic Canada and 4 in the territories. Of these facilities, only those in the territories and one in Atlantic Canada are located in rural areas. There is no facility in Prince Edward Island.

The results paint a starker picture than researchers expected, says coinvestigator Dr. Edith Guilbert, a senior medical advisor at the National Institute of Public Health of Quebec. "We knew about PEI and we knew that access was difficult in New Brunswick, but now we have real data showing that it's not just an Atlantic matter - the number of providers in the other English-speaking provinces is quite low."

It's also the first clear evidence that a

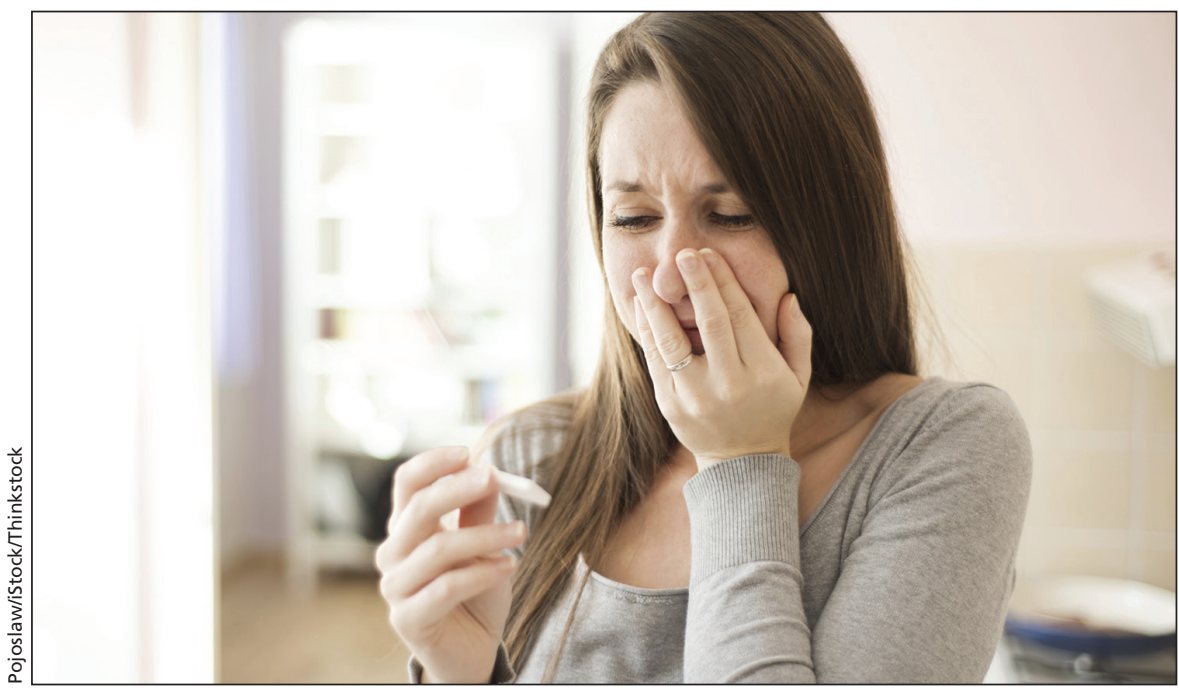

Outside Quebec, it can be a long road from confirming an unwanted pregnancy to accessing the means to end it.

laissez-faire approach to abortion provision doesn't ensure equitable access. Since the 1970s, Quebec has dedicated funds to establish abortion clinics in underserved areas. And in the 1990s, $\mathrm{BC}$ legislated which hospitals must offer abortion services to ensure rural and remote access. Both provinces support provider networks, and in BC there's a hotline women can call to connect with the nearest facility in the network.

"These are the only jurisdictions where the proportion of rural facilities is equal to or greater than the proportion of women living in these areas," says co-investigator Dr. Wendy Norman, who holds the Canadian Institutes of Health Research/Public Health Agency of Canada chair in applied public health research.

This means women wait longer and travel farther, which puts them at higher risk of having a second trimester abortion and its associated complications. And for those without the resources or time to navigate the system, it may mean carrying an unwanted pregnancy to term.

"Canada has never counted the costs being incurred ... when abortion services aren't accessible," says Norman.

Guilbert says that increasing access to medical abortion - that is, abortion induced by oral medication - could close some of the gaps in rural access because a local family doctor could administer the drug.

Yet barely $4 \%$ of abortions in Canada are done this way, compared with more than half in some peer nations, such as France. This is largely because the best abortion drugs are not available in Canada - "we are relying on medications that are not optimal," says Guilbert.

Health Canada has been considering whether to approve mifepristone (known as RU-486) since December 2012. According to a CMAJ commentary (2013;186:13-14), the drug is considered the gold standard for inducing safe and early nonsurgical abortion. But Canadian physicians must rely on less effective drugs ordinarily used to treat ectopic pregnancy, or in some cases, cancer.

"These are slow to act, and when you explain to women it's going to take two or three weeks or more before the abortion is complete, they very quickly opt for a surgical abortion," says Guilbert.

Norman argues that Canada is "not providing top-notch access for women to the full range of reproductive services across Canada." - Lauren Vogel, CMAJ

CMAJ 2015. DOI:10.1503/cmaj.109-4947 